\title{
Estudos de Psicologia
}
Revista Quadrimestral do Instituto de Psicologia e Fonoaudiologia - PUC-Campinas
Vol 18
Número 1
Janeiro/Abril 2001

\section{SUMÁRIO}

\section{Artigos}

5 Casamento e família de origem: lealdade invisível Rosicler Borghetti, marilse Brickstedt lech, Paulo César Ribeiro Martins

12 A esquizofrenia e seu tratamento farmacológico

Cilene Rejane Ramos Alves, Maria Teresa Araújo Silva

23 Disciplinas de Psicologia em cursos de graduação de enfermagem Ana Maria Pimenta Carvalho, Emília Tiemi Fukushima

37 Atitudes frente ao computador: elaboração e validação de uma escala de medida Valdiney Velôso Gouveia, Josembreg Moura de Andrade, Fabiana Queiroga, Maja Meira

46 Trabalho docente e valores: em questão as novas tecnologias de informação e comunicação Sônia Maria Guedes Gondim

58 A imagética Kinetica e mental em praticantes de desportos coletivos e individuais José Vasconcelos Raposo, Goreti Costa e Isabel Mourão Carvalhal

76 Contributos da psicologia para o estudo na disciplina na sala de aula Suzana Nunes Caldeira, Isabel Estrela Rego

\section{Resenha}

97 Plantão Psicológico, novos horizontes

Rosilene Linares 



\section{Estudos de Psicologia}

Revista Quadrimestral do Instituto de Psicologia e Fonoaudiologia - PUC-Campinas

\section{CONTENTS}

\section{Artigos}

5 MARRIAGE AND ORIGIN FAMILY: INVISIBLE LOYALTY Rosicler Borghetti, Marilse Brickstedt Lech, Paulo César Ribeiro Martins

12 Pharmacological treatment of schizophenia Cilene Rejane Ramos Alves, Maria Teresa Araújo Silva

23 Psychology courses of nursing programmes Ana Maria Pimenta Carvalho, Emília Tiemi Fukushima

$37 \quad$ Attitudes towards computer: elaboration and validaton of scale Valdiney Velôso Gouveia, Josembreg Moura de Andrade, Fabiana Queiroga, Maja Meira

46 Teacher's work and values; in the light of new information and communication technologies Sônia Maria Guedes Gondim

58 Mental and kinetic imagery among atheletes of collective and individual sports José Vasconcelos Raposo, Goreti Costa e Isabel Mourão Carvalhal

76 A psychological approach to the understanding classroom disruptive behavior Suzana Nunes Caldeira, Isabel Estrela Rego

\section{Reviews}

97

Plantão Psicológico, novos horizontes Rosilene Linares 



\title{
CASAMENTOE FAMÍLIADEORIGEM: LEALDADE INVISÍVEL
}

\author{
MARRIAGE AND ORIGINFAMILY: INVISIBLE LOYALTY
}

\author{
Rosicler BORGHETTI ${ }^{1}$ \\ Marilise Brockstedt $\mathrm{LECH}^{2}$ \\ Paulo Cesar Ribeiro MARTINS ${ }^{3}$ \\ "O casamento não surgiu sem mais nem menos. \\ Foi criado pelo homem, para atender suas necessidades." \\ O'Neill e O'Neill
}

\begin{abstract}
RESUMO
O tema "casamento e família de origem" surgiu a partir de observações feitas no atendimento de um casal, cuja queixa principal de um dos cônjuges era o fato do outro permanecer mais "casado" com sua família de origem do que com ele - embora ambos estivessem ligados às suas famílias. Esse fato acabou por se refletir negativamente em suas vidas causando-Ihes sofrimento, o que os levou a procurar ajuda terapêutica. O caso clínico caracteriza-se pela lealdade invisível em relação à família de origem, que funciona como amarras, impedindo o desenvolvimento do casal.
\end{abstract}

Palavras-chaves: casamento, família, terapia de casal e família.

\section{SUMMARY}

The theme, marriage and origin family, appeared from observations in the attendance of a couple, whose main complaint of one of the spouses was the fact of that the other remains more "married" to the origin family than to the spouse -although both were tied to their families. This fact reflected negatively in their lives, causing them suffering, making them seek therapeutic help. The clinical case is characterized by the invisible

\footnotetext{
(1) Formação em Terapia de Família e Casal pelo CEF de Porto Alegre, Profa. do CEF - Centro de Estudos da Família de Passo Fundo - RS.

(2) Especialista em Educação Infantil, Profa. da Universidade de Passo Fundo - RS.

(3) Mestre em Psicologia Clínica pela PUC-Campinas, Prof. da Universidade Luterana do Brasil - Torres - RS.

Endereço para correspondência: CEPAP - Centro de Estudos, Prevenção e Atendimento Psicológico - Rua Bento Gonçalves, 297 - conj. 809-810 - 99010-010 - Passo Fundo - RS - Fone/FAX: (54) 311-1713/311-7129 - e-mail: cepap@tpo.com.br.
} 
loyalty in relation to the origin family, which works as ties, impeding the couple's development.

Key-words: marriage, family, couple therapy and family

\section{INTRODUÇÃO}

O casamento é entendido como uma união consensual ou união com legitimação civil e/ou religiosa. Na escolha dos parceiros a atraçãoéseletiva, entrando em cena conteúdos conscientes e inconscientes (Anton, 1991; Costa e Katz, 1992; Dall'agnol, 1998). Boa parte dos motivos da escolha fica retida no inconsciente. O que habitualmente ocorre éa percepção de motivos conscientes, que ficam na face externa "de uma verdade" composta de muitas camadasquese superpõem, se ocultam e se protegem umas às outras.

Todo o sistema cria e nutre ilusões, rituais enormas de comportamento que tendem aestimular e, ao mesmo tempo, inibir o pleno desenvolvimento do indivíduo. Asobrecarga de contradições inconscientes impede, muitas vezes, saídas adequadas para asnecessidades pessoais, podendo originar dificuldades ou fracassos na escolha do parceiro, manutenção eevolução do relacionamento. Existem fatores que se interpõem entre o desejo e a possibilidade de que a relação seja assumida e cultivada. Entre esses fatores estão: a capacidade em optar pela realização de alguns desejos e de renunciar a outros; a capacidade de suportar e elaborar certo número de frustrações; o zelo e a responsabilidade pelas escolhas feitas, ea presença de necessidades contraditórias originárias da infância (Anton, 1991).

Costa e Katz (1992) afirmam que as experiências infantis estão marcadas por satisfações, frustrações e conflitos não resolvidos. A criança, antes de descobrir o eu, descobre a mãe, o pai, o irmão, enfim, sua família. Aqualidade dos vínculos estabelecidos no convívio familiar configuraum padrão básico de relacionamento na mente da criança, o qual ela terá tendência a repetir ou recriar ao longo de sua vida, independente do cenário. O casamento configura-se como cenário perfeito para que o modelo infantil de relacionamento seja revivido; o indivíduo torna-se protagonista da admirada, invejada e excludente relação dos pais.

Desde a história geracional, "que é transmitida a cada um de nós ao nascer, já existe, de uma forma invisível, a semente de uma futura sintomatologia, principalmente se levarmos em conta o modo como a família se organiza em torno daquele(a) que receberá determinada missão" (Groisman, 1996, p. 17). Antes de nascer, a criança já é depositária de uma série de expectativas, tanto do subsistema casal, quanto das famílias de origem dos respectivos pais.

De acordo com Costa e Katz (1992, p.27) "mesmo um casamento bem sucedido nunca deixará de representar uma tentativa de repetição de experiências e conflitos infantis. Na verdade o desejo de acasalar-se não passa de uma repetição de uma experiência da infância com um casal fortemente idealizado quanto às suas capacidades de mútua satisfação, que vão gerar na criança uma série de sentimentos conflitivos. Por isso se diz que o conflito é inerente ao casamento; mas é fundamental que se tenha presente em todas as situações que, repeti-lo,também representa uma tentativa de resolvê-lo".

Para Groisman (1996) as famílias possuem suas próprias leis, que fazem parte do sistema familiar herdado e desenvolvido pelos pais e filhos na atual família nuclear. Este padrão de relacionamento, segundo Nagy e Spark (1983), cria uma rede de obrigações através deumacontínuatroca de expectativas 
entre o indivíduo e o sistema de relações a que elepertence, queéresponsável pelaconstrução de uma contabilidade que mantém o sistema familiar através de um balanço imaginário. Cada membro da família acha-se subordinado a expectativas que irá cumprir, ampliar ou às quais irá reagir, de algum modo. No equilíbrio entre as expectativas familiares, as possibilidades e desejos de cada um em cumpri-las, reside o maior ou menor sucesso de realização de cada missão.

O casamento representa, para cada um dos membros do casal, a efetivação de um processo de separação e individualização, que tem seu início dentro das famílias de origem (Carter e McGoldrix, 1995). Cada parceiro procura se afastar de sua família de origem, ao mesmo tempo que busca uma aproximação com o outro para formar aunidade conjugal. Nagy, Spark (1983) e Costa (1997) afirmam que o casal vive um conflito entre a lealdade à sua família de origem e à família constituída. A busca de identidade própria do casal e um relativo afastamento das famílias de origem são parâmetros que marcam a solidificação do subsistema casal.

Bowen (1978) refere-se ao casamento como um processo de individualização que ocorre a partir da separação da família de origem e formação da unidade casal. Para a formação dessa unidade é necessária a permissão implícita ou explícita dos pais.

$\mathrm{Na}$ medida em que o casal vai consolidando paulatinamente sua família nuclear, segundo Groismain (1996), vai provocando a perda de poder dos pais, que passarãogradualmente deumaposiçãoatuante a uma posição de consultores mais passivos em relação a seus respectivos filhos.

McGoldrick (1989) diz que tornar-se um casal é uma das tarefas mais complexas e difíceis do ciclo de vida familiar. A visão romântica desta transição traz dificuldades, uma vez que todas as pessoas - desde o casal até a família e os amigos - querem ver apenas a felicidade da mudança. Os problemas podem permanecer escondidos para vir à tona mais tarde.

O casamento, muitas vezes, é visto como o rito de passagem que pode solucionar problemas como solidão ou dificuldades com a família ampliada (tios, avós...). McGoldrick (1989) diz que muitas questões têm que ser renegociadas pelo novo casal, entre elas as decisões a respeito das tradições rituais familiares que serão mantidos e outros que os parceiros desenvolverão sozinhos. relacionamento com pais, irmãos, amigos e família ampliada também tem que ser renegociado. Isso provoca nas famílias um estresse que não é pequeno. A família precisa abrir-se para um estranho e a ameaça desta mudança pode afetar profundamente o estilo de uma família.

O casamento transforma o relacionamento de uma união privada para a união formal de duas famílias (dois sistemas complexos). As questões que os parceiros não resolveram com suas próprias famílias provavelmente serão fatores importantes na escolha conjugal e interferirão no estabelecimento de um equilíbrio conjugal. Seguindo o pensamento de McGoldrick (1989), podemos dizer que os padrões familiares contribuem paraa capacidadede cada membro negociar a transição para a condição de casal. O fracasso em permitir que a outra pessoa possa se diferenciar decorre de jamais termos conseguido nos tornar independentes, em termos emocionais, de nossos pais.

Barker (1978) refere-se, como eventos familiares, aos casamentos como as maiores cerimônias organizadas pela própria famíliae são estas cerimônias que envolvem o maior planejamento. McGoldrick (1989) diz que a organização do casamento reflete o processo familiar quem fará quais arranjos, quem serão os convidados, quem paga, quanta energia emocional é investida nos preparativos, quem fica aborrecido e por quais motivos). 
Geralmente, parece que aqueles que casam de maneira não-convencional em cerimônias civis, ou sem a família ou amigos presentes têm suas razões. Quase sempre os motivos nestas situações são: desaprovação familiar, gravidez pré-conjugal, uma decisão impulsiva de casar, um divórcio anterior e má vontade dos pais de pagar os custos do casamento por incapacidade interna. Oônus emocional dessas situações, quando faz com que seja reduzida a importância do casamento, indica provavelmente, que os membros dafamília são incapazes de fazer as mudanças de status necessárias para se adaptarem a este novo estágio de ciclo de vida e que terão dificuldades em estágios futuros.

Como já foi dito anteriormente, por McGoldrick (1989), o casamento representa uma mudança no status de todos os indivíduos que fazem parte da família e alguns o consideramaúnicaalternativade se separarem de suas famílias de origem; estes tendem a se emaranhar com as mesmas. Esse padrão de funcionamento continua existindo depois do casamento. Nesses sistemas são típicos padrões de culpa, a intrusividade e fronteiras confusas. Outros casais resolvem romper emocionalmente com suas famílias até mesmo antes do casamento. Nesses casos os pais nem sequer podem ser convidados para a cerimônia, pois são vistos como estorvos. Um outro padrão envolve o contato continuado com os pais, mas com conflitos permanentes. Em tais famílias o que ocorre, normalmente, éo envolvimento da família ampliada (primos, tios, avós) nos planos de casamento, embora isso, freqüentemente, seja com brigas, sentimentos feridos e cenas, quando o casamento está se aproximando. Neste caso o conflito indica que pelo menos a família está lutando com a separação e não a encobrindo, como ocorre nas famílias emaranhadas ou com rompimentos.

A situação ideal, raramente encontrada, é aquela em que os companheiros tornam-se independentes de suas famílias de origem antes do casamento, não deixando de ter com ela laços estreitos e carinhosos. Quando isso acontece, o casamento serve paraque afamília toda compartilhe e celebre a mudança de status do novo casal.

\section{CASO ClíNICO}

\section{Motivo da procura:}

C. acusava J. por estar mais casado com sua família de origem do que com ela e decidiuse pelo divórcio. J. não aceitou e sugeriu uma terapia de casal.

\section{História familiar:}

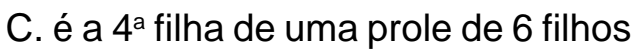
legítimos e um adotivo. O pai é agricultor e a mãe dona de casa. Não se refere aos irmãos pelo nome, chama a mais velha de "comandante", um de "ponderado", o outro de "dodói" e assim por diante. Quanto a si, intitulase "ovelha negra" e diz que veio balançar a estrutura da família.

J. é o nono filho de um total de 12 irmãos. Aos 12 anos saiu da casa dos pais e foi viver com um tio que morava na cidade. Todo o dinheiro que ganhava mandava para a família em função do pai ter adoecido. J. abriu mão da herança, após a morte do pai, por ter sido criticado pelos irmãos, que alegaram que ele não precisava dela. A herança ficou com a irmã menor que cuida da mãe.

C. e J. tiveram pouco tempo de namoro o qual foi bastante conturbado, pois a família de J. nunca aceitou que se casassem, alegando que ela nãoerauma moça direita. O casamento ocorreu há 13 anos num clima de desconforto. Muitos dos familiares de J. não foram convidados para a festa. 


\section{Evolução do tratamento:} defesas.

a) Primeira sessão - Desmantelando

O descrédito de $C$., em relação a ser ajudada, é grande e o ressentimento para continuar investindo na relação faz com que se coloque numa posição defensiva.

J. de cabeça baixa com os olhos umedecidos, fala pouco e quando tenta é interrompido bruscamente por C., para quem ele não é competente para colocar as coisas como realmente acontecem.

Observa-se que J. é tratado por C. como um menino. C. acusa-o de nunca estar ao seu lado quando precisa, não a defende em situações familiares quando é vítima de piadas de mau gosto por parte dos cunhados(as). C. gostaria que $\mathrm{J}$. a assumisse como sua mulher perante a família dele, defendendo-a nessas situações. "Eu busco pelo menos o olhar dele, mas não encontro nada porque ele abaixa a cabeça e não faz nada, então tenho que me defender sozinha". J. diz que fica imobilizado, sabe que teria que reagir pedindo que respeitassem sua mulher, mas algo o impede de fazê-lo.

b) Segunda sessão - A gatinha disfarçada de ovelha negra.

Pela construção do genograma, C. reconhece que ser a ovelha negra foi a única forma de encontrar seu espaço eser respeitada dentro da família. Principalmente pelo pai que venera a filha mais velha, da qual $\mathrm{C}$. tem muito ciúmes. Por trás da máscara da ovelha negra existe uma "gatinha" pedindo para ser olhada e aceita como é. C. escolhe um companheiro cuja família não a aceita; com isso, continua na família de J. uma brigaque iniciou na dela, para ser aceita, receber carinho e atenção.

c) Terceira sessão - Será que o bife maior pode ser meu?

J. coloca que sempre se sentiu responsável pelos irmãos, e levou muito tempo para reconhecer que alguns deles fazem tudo para perturbar a paz de sua família atual. Relata que sempre procurou agradar a todos e que as discussões de sua família com $\mathrm{C}$. 0 entristece. Tem preferido manter-se neutro porque reconhece que sua esposa sempre se defendeu sozinha. C. briga pelos dois, diz coisas que J. também gostaria de dizer, mas que não se sente em condições por ter que ser sempre o "bom menino", aquele que não desagrada nunca. J. está pagando caro pela desobediência a sua família, através de sua infelicidade no casamento, o qual não foi aprovado pelo pais.

J. contaque foiensinadosempreacomer o menor bife e que isso o atrapalha até hoje, tanto que deu toda sua herança para a irmã mais nova.

C. sente-se sozinha e cansada e J. impotente para saborear o bife que vem conquistando durante esses anos todos. $\mathrm{O}$ fato de J. ter se diferenciado de seus irmãos pela posição social que ocupa, faz com que se sintaculpado, além de abandonado pelafamília, o que o impede de ocupar o seu lugar dentro de sua família nuclear.

d) Quarta sessão - É difícil sair da casa de nossos pais!

J. chega à sessão com um novo visual, um novo corte de cabelo e roupas de cores mais vivas. Relata que decidiu usar as roupas quetemguardadasem seuarmário, compradas pela esposa, já que antes não se preocupava emficarbonito. C.é quem sempre se preocupou com as roupas de J.. Ela diz que J. andava como um mendigo. J. relata que na casa de seus pais foi ensinado a trabalhar e não ter mais de duas camisas para vestir.

Durante a sessão, C. revela que não sente que J. tenha saído da casa de seus pais, como também não sente o marido ao seu lado. J. discorda, dizendo que atualmente já não está tanto na casa de seus pais. Vem percebendo que está conseguindo se afastar 
aos poucos das obrigações impostas pela famíliadeorigem. Atualmenteestáaproveitando melhor suas conquistas. C. diz estar gostando dessas mudanças porque cansou de vê-lo feito um capacho diante de sua família, para quem ele sempre diz amém. $C$. comenta que deseja um homem que olhe nos seus olhos, que lhe dê atenção. O terapeuta pergunta por quemmais gostaria de ser olhada. C. reconhece que o olhar que busca é o olhar de seu pai.

C. e J. estão conflituados com suas famílias de origem. Ambos depositam expectativas que possuem, como filhos, numa relação que exige que eles assumam as funções de homem e mulher.

\section{DISCUSSÃO DO CASO}

O casal chega à terapia na qual o desejo e a decisão de separar-se não são mútuos. C. verbalizavaquequeriaaseparação, masestava ali não para concretizá-la, mas para ver o que poderia ser feito para que a mesma não se concretizasse.

C. e J. não estão juntos por acaso na escolha que fizeram. Boa parte do motivo está retido no inconsciente, o que faz com que eles enfrentem sua nova relação com toda uma bagagem de antigas relações. C. não consegue largar sua função de ovelha negra, ao passo que J. não larga sua função de bom menino, funções essas já desempenhadas em suas famílias de origem. C. procurou ser a ovelha negra também nas sessões, não ouvindo, gritando quando não concordava com alguma coisa e não permitindo que o marido expusesse suasopiniões. Este, porsuavez, fazia o papel de bom menino, aceitando tudo isso como se realmente não tivesse valor algum.

Para que possamos entender o que ocorrecom C.e J.éfundamental que tenhamos clareza do que Elkain (1988) chama de programa oficial (P.O.) e mapa do mundo
(M.M.). O primeiro, conforme o autor, seria a demanda explícita do casal e, o segundo, as crenças inseridas em cada membro do casal, conseqüências de suas histórias, de suas experiências anteriores ao casamento.

Cada membro do casal está preso pela contradição em dois níveis de expectativa: C. pede a J.: "me olha, me defende". Quando J. responde a esse pedido, auxiliando-a em qualquer situação, ele obedece ao programa oficial de C., mas não ao seu mapa de mundo, e ela só pode, então, recusar essa ajuda, pois uma "ovelha negra" sabe muito bem defenderse sozinha. Nesses momentos C. acusa J. de incompetente e incapaz, afastando-o.

Por sua vez, J. pede a C.: "quero ser respeitado". Quando C. permite que alguma decisão importante seja tomada por ele, está obedecendo o seu programa oficial, mas não ao seu mapa do mundo, e ele só pode recusar essa situação. Nesses momentos, não consegue tomar decisão alguma, ficando paralisado e, pedindo a opinião da esposa para tudo. Coloca-se como o "bom menino", afastando-a. Quando ela se defende sozinha, em situações familiares em que é agredida, corresponde ao mapa de mundo de J., mas não ao seu programa oficial.

Conforme Elkaim (1988), o casal corresponde a uma parte visível de um sistema bem mais amplo, ou seja, as famílias de origem têm importância fundamental nos elementos que suscitam e mantêm o conflito. C. e J. parecem reproduzir entre eles padrões de funcionamento existentes nas famílias de origem que, apesar de aparentemente diferentes, num nível mais profundo, expressam suas semelhanças, ou melhor, ambos possuemum medomuito grande de se ligarem, de assumirem um compromisso e de não serem aceitos, de serem abandonados.

J. e C. buscam o reconhecimento de suas famílias paraque possam existir enquanto indivíduos e se tornarem um casal. 
Carter e Mc. Goldrick (1995) explicam que, no casamento, cada um dos parceiros vive o paradoxo de, ao mesmo tempo em que procura se afastar de sua família de origem, busca a aproximação com o outro para formar a unidade conjugal. A existência dessa unidade não depende só do homem e da mulher, mas da permissão, explícita ou não, dos pais, para que os filhos cresçam e tenham sua própria família. J. e C. casaram contra o desejo da família de J. Embora esse ato tenha sido a maior desobediência do "bom menino", é algo que o impede de saborear, sem culpa, o "grande bife" que conquistou. Para C., essa situação é a oportunidade de continuar lutando pelo seu espaço, luta esta que travou desde menina a fim de ser olhada pelo seu pai.

\section{CONCLUSÃO}

Deacordo com Andoldfie Angelo(1977), através do novo relacionamento é possível elaboraráreas de dependênciasnão resolvidas nos relacionamentos originais, pela necessidadequeos envolvidostêm deenfrentar constantemente o problema, na tentativa de resolvê-lo ou transformá-lo. Portanto, se a ligação que se instaurou deve sua força aos conteúdos problemáticos das relações anteriores, a resolução destes problemas pode implicar o risco de, em parte, esvaziar o significado da relação atual.

O casal em questão, se dispôs a correr o risco de esclarecer o significado de sua relação. Necessariamente teve que ocorrer a separação de suas famílias de origem. J. e C. estavam aprisionados à opinião familiar de que não poderiam formar um verdadeiro casal. $\mathrm{O}$ casal se dispôs a suportar a idéia de se separar aos poucos de suas famílias de origem. Embora a dor fosse grande, esse foi o preço a ser pago para o desenvolvimento de cada um deles como indivíduos únicos e também para o crescimento de ambos como casal, digno de respeito e de ser feliz.

\section{REFERÊNCIAS BIBLIOGRÁFICAS}

ANDOLFI, M., ANGELO, C., SACCU, C. O casal em crise. São Paulo, Summus, 1995.

ANTON, C. I.A escolhado cônjuge. Motivações inconscientes. Porto Alegre, Sagra, 1991.

BOWEN, M. Family therapy in clinical practice. Nova York, Jason Aronson, Inc., 1978.

CARTER, B. e MCGOLDRICK, M. As mudanças no ciclo de vida familiar - uma estrutura para a terapia familiar. Porto Alegre. Artes Médicas, 1995.

COSTA, P. G. Conflitos da vida real. Porto Alegre, Artes Médicas, 1997.

COSTA, P. G., KATZ, G. Dinâmica das relações conjugais. Porto Alegre, Artes Médicas, 1992.

DALL'AGNOL, R.de S. Avaliação e tratamento em terapia conjugal. Psico. 29(1),139-153, 1998.

ELKÃIM, M. Se tu me amas, não me ames. Campinas, Papyrus, 1988.

GROISMAN, M., LOBO, V. M., CAVOUR, M. R. Histórias dramáticas. Terapia breve para famílias e terapêutas. Rio de Janeiro, Rosa dos Tempos, 1996.

NAGY, I. B. e SPARK G. M., Lealdades Invisibles. Buenos Aires. Amorrortu, 1983. 